\title{
DESIGN, PONTO DE VISTA E PERSPECTIVAS: SOBRE A CULTURA DO PROJETO, EDUCAÇÃO E ATUAÇÃO PROFISSIONAL
}

\author{
Teresa Maria Riccetti \\ Universidade Presbiteriana Mackenzie \\ teresamaria.riccetti@mackenzie.br \\ Nara Silvia Marcondes Martins \\ Universidade Presbiteriana Mackenzie \\ narasilvia.martins@mackenzie.br \\ Luís Alexandre F. Ogasawara \\ Universidade Presbiteriana Mackenzie \\ luis.alexandre@mackenzie.br
}

Resumo: A pesquisa desenvolvida por docentes e discentes da Universidade Presbiteriana Mackenzie com fomento do MackPesquisa, no período de março de 2015 a maio de 2016 teve como escopo compreender o status quo do design, no contexto da nossa realidade social, econômica e cultural. Delinear proposições sob as futuras fronteiras do sistema design e prospectar as áreas que serão relevantes à atuação profissional para as próximas décadas. A relevância em discutir o sistema design diante da atual configuração tem por intuito gerar uma contribuição condizente com a dinâmica contemporânea que possibilite nortear a construção de futuros caminhos pedagógicos, investigativos e profissionais; provendo dados para incrementar a prática docente e o aprendizado discente de um campo em permanente evolução, como a do design.

Palavras-chave: Design, Cultura do Projeto, Atuação Profissional, Ensino.

Abstract: The research developed by teachers and students of the University Presbteriana Mackenzie with promotion of MackPesquisa, from March 2015 to May 2016 had the scope to understand the status quo of Design, in the context of our social, economic and cultural reality. Outlining proposals under the future borders of the design system and exploring the areas that are relevant to professional performance in the coming decades. The relevance to discuss the design on the current system configuration is meant to generate a consistent contribution to the contemporary dynamics that allows guide the construction of future educational, investigative and career paths; providing data to improve teaching practice and student learning in a field in constant evolution, such as design.

Keywords: Design, Design Culture, Professional Practice, Education. 


\section{INTRODUÇÃO}

Proprio come il sale, um pizzico di design sta bene quase dappertutto, e questo spiega perche il design sai così difusso, anzi pervasivo e trasversale... (TRABUCCO, 2015, p.13) ${ }^{1}$

No decorrer dos séculos a evolução do design sempre esteve associada aos contextos econômicos, político, social e cultural da época. Atualmente a complexidade do sistema design é grande e abrange uma trinca de elementos complexos - a cultura do projeto, o ensino e o mercado de trabalho; esta equação é inerente a formação e atuação profissional do designer.

O estudo desenvolvido por docentes e discentes integrantes do grupo de pesquisa: Design, teoria e projeto do Curso de Design da Universidade Presbiteriana Mackenzie no período de fevereiro 2015 a maio de 2016 teve como escopo compreender o status quo do Design, no contexto da nossa realidade socioeconômica e cultural.

A relevância em se discutir o design diante da atual configuração do Sistema Design - compreende sua definição e mapeamento de suas áreas e subáreas de performance; e sua inter-relação com o ensino e a prática projetual.

A questão é complexa e compreende o descompasso entre elementos importantes à prática do design; como ilustração deste cenário o estudo foi direcionado por quatro pontos relevantes, que serão detslhados mais a frente.

Quadro 1 - Os quatro pontos norteadores do estudo.

\begin{tabular}{|c|l|}
\hline Ponto 1 & A atual complexidade do sistema design \\
\hline Ponto 2 & O processo produtivo e o desenvolvimento tecnológico \\
\hline Ponto 3 & A questão do ensino e o dinamismo do sistema design \\
\hline Ponto 4 & Atuação profissional \\
\hline
\end{tabular}

Fonte: "Elaborado pelo autor, com base na pesquisa realizada"

A compreensão pormenorizada destes pontos nos possibilita apreender os seguintes objetivos:

- Indicar o (s) ponto (s) de vista atual sobre a percepção do sistema design e sua inserção nas esferas do ensino e mercado de trabalho;

- Delinear as perspectivas sobre o futuro do sistema design quanto as inovações tecnológicas, a educação e a atuação profissional do designer para as próximas décadas;

- Gerar um estudo que propicie uma contribuição condizente com a dinâmica contemporânea e que possibilite nortear a construção de futuros caminhos pedagógicos, investigativos e profissionais na área do Design;

- Fortalecer a área do ensino e pesquisa de Design provendo dados para incrementar a prática docente e o aprendizado discente de uma área em permanente evolução, como a do Design que aborda o planejamento e desenvolvimento de projetos de objetos artificiais voltados às necessidades dos indivíduos e da sociedade;

\footnotetext{
${ }^{1}$ Assim como o sal, um toque de design vai muito bem por quase toda parte; e isto explica porque o design é tão difuso, de fato generalizado e transversal. (TRABUCCO, 2015, p.13 tradução nossa)
} 
- Propiciar a produção de produtos derivados do presente estudo como artigos científicos; projetos de TCC e IC com argumentos mais condizentes com a dinâmica contemporânea e que possam ser utilizados na prática docente e discente no curso de Design da Universidade Presbiteriana Mackenzie, Graduação e PósGraduação.

\section{METODOLOGIA E PROCEDIMENTOS}

De natureza qualitativa o estudo empregou técnicas da pesquisa documental com coleta e compilação da literatura - estudos, artigos científicos e publicações sobre o sistema design, status quo e perspectivas futuras. Destacam-se nessa etapa de referencial teórico, as obras dos teóricos De Fusco (2012); Trabucco (2015); Morace (2013); Margolin (2014); Branzi (2013). Os estudos - "Diagnóstico do Design Brasileiro" (2014) e "O futuro do design no Brasil" organizado por Silva et al (2012). Essas obras endossam o referencial teórico que aborda a pluralidade, e a complexidade do atual sistema design em uma perspectiva glocal.

A amostra é caracterizada por personalidades profissionais brasileiros atuantes no mercado e ou docência totalizando 29 entrevistados.

A aplicação dos questionários deu-se, prioritariamente, por e-mail ou presencialmente cujos resultados foram transcritos e organizados em tabelas seguindo um alinhamento entre a questão referente e as respectivas respostas. A reunião de toda a documentação levantada e selecionada evidenciou e balizou pontos importantes para o estudo.

\section{SINTESE DOS RESULTADOS E DISCUSSÃO}

Para a discussão dos 4 pontos norteadores da pesquisa foram realizados questionários com 3 perguntas para cada ponto.

Quadro 2 -As questões que integraram o questinário

\begin{tabular}{|c|c|}
\hline \multicolumn{2}{|r|}{ Ponto $1 \mathrm{~A}$ atual complexidade do sistema design } \\
\hline 1 & Como $_{(a)}$ senhor $_{(a)}$ vê o Design no Brasil? \\
\hline 2 & Que projeção o $\left(\right.$ a) senhor $_{(a)}$ faz para o Design brasileiro? \\
\hline 3 & $\begin{array}{l}\mathrm{O}_{(\text {a) }} \text { senhor }_{(\mathrm{a})} \text { considera que a pluralidade do sistema design beneficia ou prejudica a compreensão, } \\
\text { pela sociedade do que seja Design hoje? }\end{array}$ \\
\hline \multicolumn{2}{|r|}{ Ponto 20 processo produtivo e o desenvolvimento tecnológico } \\
\hline 4 & $\begin{array}{l}\text { De que modo a expansão do acesso a tecnologias produtivas, podem impactar na atividade do } \\
\text { design? }\end{array}$ \\
\hline 5 & $\begin{array}{l}\text { Quais os princípios metodológicos que } \mathrm{o}_{(\mathrm{a})} \text { senhor }_{(\mathrm{a})} \text { considera essenciais para o desenvolvimento } \\
\text { de um projeto? }\end{array}$ \\
\hline 6 & De que forma a tecnologia, o computador modificou de algum modo seu processo projetual? \\
\hline \multicolumn{2}{|r|}{ Ponto 3 A questão do ensino e o dinamismo do sistema design } \\
\hline 7 & $\begin{array}{l}\text { Tendo em vista o perfil dos designers recém formados, o que } \mathrm{o}_{(\mathrm{a})} \text { senhor }{ }_{(\mathrm{a})} \text { acha que as escolas de } \\
\text { graduação precisam suprir para formar um profissional apto? }\end{array}$ \\
\hline 8 & $\mathrm{O}_{(\mathrm{a})}$ senhor $_{(\mathrm{a})}$ acredita que a pesquisa científica pode contribuir com a prática do designer? \\
\hline 9 & $\mathrm{O}_{(\mathrm{a})}$ senhor $_{(\mathrm{a})}$ identifica momentos importantes na sua formação? \\
\hline \multicolumn{2}{|c|}{ Ponto 4 Atuação profissional } \\
\hline 10 & Quais são os pontos fortes e os pontos fracos do designer brasileiro? \\
\hline 11 & $\mathrm{O}$ que $\mathrm{O}_{(\mathrm{a})}$ senhor $_{(\mathrm{a})}$ diria à um jovem designer que enfrenta hoje o mundo do trabalho? \\
\hline 12 & Qual a sua opinião sobre a regulamentação da profissão do designer no Brasil? \\
\hline
\end{tabular}




\subsection{Ponto 1 - A atual complexidade do sistema design}

Este é o primeiro ponto proeminente do estudo, a própria complexidade do atual sistema design. Segundo De Fusco (2012, p.27) "não existe apenas um design, mas tantos quantos são os campos merceológicos ${ }^{2 "}$. Em sua pluralidade e multifacetas, o sistema design não se circunscreve apenas nas tradicionais categorias - industrial, gráfico, produtos e moda. Hoje, agregam-se a orbe deste sistema - o design da informação, o design estratégico, design de espaço, design social, e outros. Cada uma destas categorias abriga mais uma série de outras subcategorias e neste sentido o design não parece ter uma trajetória definida, como relatado por Silva et al. (2012, p.45), "O design se torna cada vez mais especializado em alguns campos, desenvolvendo competências específicas, mas ao mesmo tempo se torna generalista em outras, com o aparecimento de formas híbridas de prática".

Síntese do Ponto 1: E como destaca a professora Myrna de Arruda Nascimento:

... não podemos falar de uma "visão do design no Brasil" como um todo, mas admitir sua fragmentação e particularidade, para cada contexto diferenciado, deste país imenso, diverso e desigual. (Entrevista concedida no dia 04/10/2015)

No Brasil, a compreensão do que seja design depende do contexto sociocultural e do repertório da comunidade em questão. Por questões históricas e geográficas, a grande extensão do território e as diferentes influencias culturais de cada região propicia uma gama diversificada sobre o entendimento do de seja e para que serve o design e o designer. É importante ressalvar que diferente de outros países que têm uma cultura de projeto consolidada, a cultura e a prática do design são recentes em nossa história; nossa industrialização tem início na década de 50 , do século $X X$, e os primeiros cursos de graduação foram criados há aproximadamente 60 anos, e em um primeiro momento ficaram circunscritos entre as cidades de São Paulo e do Rio de Janeiro. Como nos relatou o designer e professor Giorgio Giorgi:

No caso específico do Brasil, o processo atribulado derivado da tardia industrialização e a consequente falta de compreensão do alcance da atividade de projeto, tem-se encarregado de tumultuar qualquer tentativa de conquista de uma instância mínima de serenidade. (Entrevista concedida no dia 05/05/2015)

Para a designer Gloria Lin, o design em sua complexidade e toda sua abrangência:

... é muito além do que pode ser compreendido por um país que ainda precisa desenvolver a sua indústria, desenvolver a sua cultura e uma população que pouco pode consumir - tanto produto quanto informação. (Entrevista concedida no dia 15/06/2015)

\footnotetext{
${ }^{2}$ A merceologia pode ser entendida como um estudo que leva em consideração a análise das características técnicas e comerciais de uma determinada mercadoria. Formalmente, divide-se em dois módulos: Módulo de Informações Técnicas e Módulo de Informações Comerciais, pelos quais se torna possível conhecer a mercadoria tanto técnica (sua identificação; suas características operacionais e usuais; seus insumos e matérias-primas utilizados; entre outros), como comercialmente (nomes usuais; canais de distribuição; comissões; preço internacional; entre outros) N. do A.
} 
Ainda hoje, o design é identificado pelo mercado de modo equivocado como algo restrito a aparência e estilo que segundo o designer e coordenador do extinto LBDI, Eduardo Barroso (2015), é pouco aproveitado em desafios de maior complexidade. O design brasileiro reflete a situação de nossa condição, em algumas áreas floresce e em outras retrocede; muito já foi feito, mas ainda temos um longo caminho a ser percorrido. Para o designer Rafael Campoy, o design está diluído:

\begin{abstract}
Observo um leque cada vez mais amplo de especialidades, tanto no mercado profissional quanto no âmbito acadêmico. Concomitante a isso, aposto no aumento da "confusão" - por parte da sociedade - do que diz respeito ao design. A alta especialização parece mais confundir e associar o design à estética e ao efêmero do que ao projeto e ao longo-prazo. (Entrevista concedida no dia 03/07/2015)
\end{abstract}

A confusão de fato aumenta quando observamos que não há um conceito estabelecido sobre, a compreensão da importância do design na vida cotidiana das pessoas; e isso reflete tanto no campo profissional, o mercado de trabalho, como no campo acadêmico, o ensino e pesquisa. Como nos relatado pelo designer e um dos coordenadores do extinto LBDI, Pedro Paulo Delpino Bernardes:

... me parece que por muito tempo continuaremos dando tiro no pe com egressos perdidos e desorientados perante o 'mercado de trabalho'. Profissionalmente o 'mercado' está absolutamente confuso exatamente porque a formação acadêmica permite inclusive por necessidade de sobrevivência, forte banalização da atuação profissional. (Entrevista concedida no dia 12/08/2015)

Para o designer e atual diretor da ESDI/UERJ Rodolfo Capeto, combinar a visão generalista com o necessário aprofundamento em conhecimentos técnicos e projetuais associados a cada linha de trabalho é um dos dilemas significativos na área do design:

... nosso entendimento é de que o campo do design, como campo específico do projeto, é integrado, e essas diferentes variedades de atuação fazem parte de um espectro contínuo. por outro lado, esse amplo escopo permite alguns aventureirismos, também por pessoas de outras áreas. (Entrevista concedida no dia 05/10/2015)

É consenso que a pluralidade do design se dá devido as suas diferentes possibilidades de atuação e aplicação transdisciplinar, mas é necessário evidenciar que sua raiz conceitual do design, como projeto e elemento da cultura material e imaterial deve ser sempre sustentada. Já quanto ao caráter multifacetado do design há uma dualidade explicitada por um lado pelo escopo de melhor compreender e aprofundar as diferentes ações, mas por outro lado dificulta a compreensão do que é o design pela sociedade.

\title{
3.2 Ponto 2 - 0 processo produtivo e o desenvolvimento tecnológico
}

O outro ponto em destaque é o processo produtivo e o desenvolvimento tecnológico, um dos quesitos básicos de qualquer tipo de projeto do objeto; que na realidade contemporânea se desprende do estigma da produção industrial. Para o designer italiano Andrea Branzi (2012, p. 106): 
... atualmente a questão da produção industrial não é mais tão relevante, pois existem a autoprodução, as séries limitadas, as pecas únicas; a qualidade intelectual de uma obra conta mais do que sua qualidade técnica. Hoje, a demanda que o projeto deve atender é a de que o objeto em questão deve ser suscetível à possibilidade de reprodução.

Síntese do Ponto 2: O design sempre foi impactado pelas transformações das tecnologias produtivas e se transformou, renovando suas atividades e ampliando o foco de atuação. No contexto histórico essas mudanças sempre contribuíram e proporcionaram novas possibilidades de projetos. $\mathrm{O}$ atual momento se delineia pela transição das tecnologias produtivas do meio mecânico para o meio digital e neste sentido essas novas técnicas são possibilidades à serem exploradas. E neste sentido o processo intelectual tende a ser mais dinâmico, agilizando e minimizando uma série de etapas do procedimento metodológico, mas para isso não se pode perder o foco de que, o design é uma atividade projetual desenvolvida pelo ser humano e para o ser humano e as questões de produção devem ser alinhadas.

É consenso de que o desenvolvimento tecnológico propicia a ampliação de mercado, o que traz inúmeros benefícios ao design. Mas como colocado pelo designer Rafael Campoy:

... O cerne da questão deve ser quanto ao uso/utilidade da tecnologia. Deve ser empregada como meio/ferramenta para o trabalho do designer, nunca como finalidade. (Entrevista concedida no dia 03/07/2015)

Nas palavras do professor Marcos da Costa Braga:

...a impressora 3D veio para substituir e tomar conta de tudo, mas não é isso ela é apenas mais uma ferramenta para atender a ramos específico de necessidade de produção de produto que existiam antes, mas não tinham essa ferramenta que agiliza teste de concepção da forma, gastando menos tempo e menos dinheiro para testar o projeto. ... A concepção continua a mesma, é mental e intelectual e deve-se se adaptar a forma de se expressar e no processo metodológico mental, porque a feramente permite pular uma série de etapas, portanto torna o processo intelectual mais dinâmico, não considero que a impressora vai substituir a produção de produtos devido ao preço etc. ela vai auxiliar no método. (Entrevista concedida no dia 05/03/2015)

O professor ainda reforça que o processo de concepção continua o mesmo, é mental e intelectual e deve se adaptar na forma de se expressar e no processo metodológico. Endossando que as novas possibilidades que os avanços tecnológicos oferecem vão interferir diretamente na linha de conduta assumida como procedimento metodológico de cada projeto; como colocado pelo designer e atual diretor da ESDI/UERJ Rodolfo Capeto:

Cada tipo de projeto demanda (ou faz criar) seu método próprio. Os antigos princípios de metodologia, boa definição do problema, pesquisa, foco no usuário, brainstormings, critica aos resultados, permanecem válidos; em todo caso, a força inventiva do designer muitas vezes atravessa o processo com uma nova ideia, que certamente deve ser sujeita aos mais duros testes antes de ser aplicada. (Entrevista concedida no dia 05/10/2015) 
Cada projeto requer uma linha de conduta por parte do designer que elege as técnicas de levantamentos, análises, experimentos mais adequados a questão colocada. Portanto, como já dizia Bruno Munari, não existe receita pronta e sim uma metodologia operacional de projeto que muitas vezes se configura concretamente quando se obtém a solução da questão. Este pensamento é compartilhado pelo designer Giorgio Giorgi:

...com tanto tempo de janela, por uma questão de honestidade devo admitir que o método empregado num determinado projeto só é conhecido retrospectivamente, ou seja ao seu final. Acredito, no máximo, na eficácia de certa estratégia metodológica. (Entrevista concedida no dia 05/10/2015)

Em síntese, o desenvolvimento tecnológico propicia um dinamismo no processo intelectual que incrementa a prática projetual e otimiza os procedimentos metodológicos.

\subsection{Ponto 3 - A questão do ensino e o dinamismo do sistema design}

Agregasse a esses pontos a questão do ensino, que por mais que se esforce, não consegue acompanhar o dinamismo do sistema design. Em 1978 a estrutura curricular chamada de currículo mínimo para cursos de graduação especificada pelo Conselho Federal de Educação - CFE; definiu a subdivisão da área de design em duas subáreas ou habilitações: Projeto do Produto e Programação Visual, mas esta resolução só foi decretada em $1987^{3}$. No presente momento os cursos de Bacharelados em Design são pautados pelas Diretrizes Curriculares Nacionais de 2004; há mais de dez anos. Mesmo com os esforços pontuais de cada instituição de ensino em design, no empenho de renovar e atualizar seus projetos pedagógicos e consequentemente suas composições curriculares, ainda há um déficit entre o que se ensina e o que é necessário à atuação do profissional. Um dilema difícil de ser equacionado devido a própria velocidade de transformação da tecnologia.

Síntese do Ponto 3: Historicamente, foi no início dos anos 70 que Tomás Maldonado, ex-diretor da Escola de Ulm, em conjunto com teóricos italianos apresenta a primeira iniciativa de apoio à autonomia do Design colocando que, o designer é caracterizado como alguém que projeta ou desenvolve projetos, ou seja, tem conhecimento da cultura do projeto. Para Margolin (2014, p. 18), "designers ocupam um espaço dialético entre o mundo que é e o mundo que poderia ser. Informados pelo passado e presente, a sua atividade está orientada para o futuro". Hoje, os designers enfrentam desafios relacionados a valores e ética; e o mundo passa atualmente por extremas mudanças e neste sentido, nós designers devemos aprender a pensar o futuro de um novo modo.

Se o mundo mudou, o ensino de design precisa mudar. Instituições de ensino em design se empenham para atualizar seus projetos pedagógicos com novas posturas, com relação ao conteúdo, adotando novas técnicas pedagógicas inclusive com o protagonismo do aluno, mas ainda assim há um déficit entre o que se ensina e o que é necessário à atuação do profissional. Um dilema difícil de ser equacionado

\footnotetext{
${ }^{3}$ Porém, como constatado na pesquisa Registro de Memória: 40 Anos do Curso de Desenho Industrial Mackenzie, 2012; com apoio do Mackpesquisa: o Curso de Design Mackenzie já havia incorporado essa resolução desde a sua definição, o que demonstra uma preocupação em estar atualizado.
} 
devido a própria velocidade de transformação da tecnologia. Segundo relatado pelo designer Cesar Robert Moraes de Sousa:

... o ensino de design no Brasil está um pouco atrasado em relação à forma
com que somos cobrados hoje em dia, isto é, os alunos estão aprendendo
numa taxa que não chega nem a $50 \%$ da taxa que somos cobrados no
meio profissional. ... Uma forma de tentar superar os currículos estáticos e
fragmentados é apostar na flexibilização da grade, permitindo que alunos
criem suas composições curriculares e determinem suas linhas de pesquisa
e estudo. (Entrevista concedida no dia $17 / 08 / 2015$ )

Em seu depoimento, o professor Marcos da Costa Braga observa que infelizmente existe uma grande parte de cursos de design que pensam em formar o profissional em menos tempo e com uma carga maior de ferramentas. Segundo Costa Braga:

...isso em teoria faria com que o aluno fosse absorvido mais rápido pelo mercado, porém isso faria dele um técnico-ferramental, ele não será um líder de equipe, será um profissional subordinado, e que estaria condicionado a ficar no mercado mediante a atualização técnica dos softwares, isso para mim é um grande equívoco na formação do designer. (Entrevista concedida no dia 05/03/2015)

Ainda segundo o professor, falta aos cursos uma formação um pouco mais próxima da viabilidade de produção, domínio de matérias primas e viabilização econômica, uma coisa difícil de se solucionar por estar amarrada aos avanços da tecnologia. Para Costa Braga, a capacidade de pensar deve ser muito maior do que a capacidade de dominar as ferramentas.

O que o profissional precisa é de uma formação intelectual maior uma capacidade de pensar, enxergar cenários, e saber se posicionar diante desses cenários, ter uma visão crítica, cultural e intelectual ampliada e saber se adaptar a situações do mercado, não é apenas domínio ferramental. Essa capacidade intelectual que deve ser estimulada. (Entrevista concedida no dia 05/03/2015)

Tendo em vista o grande número de formandos em design a cada ano e concomitante as questões especificas da atividade, o professor Rodolfo Capeto declara que:

...um esforço de construção de base cultural, no mais amplo sentido, é parte importante da formação de designers que possam fazer diferença no mundo contemporâneo, especialmente tendo. (Entrevista concedida no dia 05/10/2015)

A última lei 9394, de Diretrizes e Bases da Educação Nacional, LDB coloca que:

O ensino superior tem por finalidade o pleno desenvolvimento do educando, seu preparo para o exercício da cidadania e sua qualificação para o trabalho, bem como deve estimular a criação cultural, o desenvolvimento do espírito científico e do pensamento reflexivo, o incentivo ao trabalho de pesquisa e a investigação científica, com vistas ao desenvolvimento da ciência e da tecnologia e da criação e difusão da cultura, e, desse modo, desenvolver o entendimento do homem e do meio em que vive, além da 
promoção e da divulgação de conhecimentos culturais, científicos e técnicos que constituem patrimônio da humanidade e comunicação do saber através do ensino, de publicações ou de outras formas de comunicação. Uma das alternativas em busca do conhecimento é o ensino através da pesquisa, desenvolvendo a autonomia dos alunos, instigando-os a questionamentos constantes (BRASIL, 1996)

A pesquisa de iniciação científica cresce nas universidades, assim como nos cursos de ensino de design, apesar de muitas vezes ser vista como produtora de textos é perceptível a mudança desta visão, conforme apontado pela designer e atual diretora do Centro de Artes da UDESC Gabriela Botelho Mager:

\begin{abstract}
... a pesquisa científica auxilia o aluno a organizar o olhar criativo, desperta a atenção para a organização do método de pesquisa, assim como a proposta do problema além do objetivo e o conceito bem definido e construído; os elementos principais da pesquisa científica contribuem para o desenvolvimento de projetos bem executados. (Entrevista concedida no dia $18 / 08 / 2015)$
\end{abstract}

A pesquisa é uma peça chave da formação dos indivíduos, preparando-os para adquirir um olhar científico e indagador, a experiência com a pesquisa científica proporciona um processo de aprendizagem de extrema complexidade, possibilita ao aluno a construção da autonomia intelectual, postura crítica e desvinculação do senso comum. Como colocado por Gustavo Curcio:

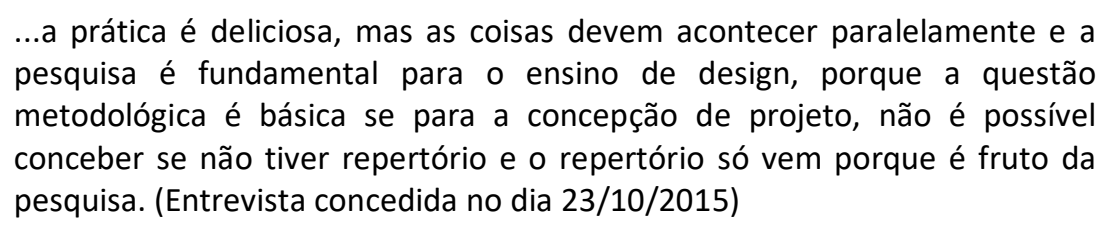

Para a entrevistada, Fernanda Jordani Barbosa Harada, o designer atuante nesta sociedade contemporânea:

\begin{abstract}
...deve ter um alto poder de observação do mundo em torno, tanto para criar um olhar formal e crítico sobre as coisas, como para compreender as deficiências do meio construído para acolher o indivíduo, e criar soluções passíveis de serem reproduzidas. Quanto maior a curiosidade, melhor a definição dos problemas. Quanto maior a capacidade criativa, maiores e melhores as soluções propostas. Quanto maior o poder de empatia com os indivíduos/usuários mais completa a solução. Quanto maior o poder de observação do mundo, melhor será o designer. (Entrevista concedida no dia 11/03/2016)
\end{abstract}

Talvez não seja realista acreditar que designers vão salvar o mundo, mas faz sentido reconhecer que o design quando práticado com consciência ética é uma das ferramentas mais poderosas da humanidade. "O design é processo que o ser humano tem usado ao longo dos tempos para desenvolver contextos necessários à sua sobrevivência e ao progresso" (MARGOLIN, 2014, p. 78). Certamente outra forma de ver o crescimento intelectual e a apreensão do conhecimento na área do design, especificamente nos aspectos projetuais, como apontado por Fernanda Harada (2015), "as escolas devem formar, curiosos, observadores, detalhistas, críticos e criativos". 


\subsection{Ponto 4 - Atuação profissional}

E por último a atuação profissional - Por sua capacidade em propor soluções criativas o design é um setor em ascensão, os avanços tecnológicos e consequentemente dos processos produtivos propiciam novas tipologias de objetos e consequentemente novas maneiras de interação do indivíduo, da sociedade com seus objetos, e neste sentido o designer se qualifica mais uma vez, como um agente importante da cultura material. Os designers deverão acentuar cada vez mais seu grau de qualificação ou da habilidade exigida para esses novos campos de atuação (SILVA et al., 2012).

Síntese do Ponto 4: Os pontos fortes creditados aos designers podem ser divididos em duas naturezas distintas, a coletiva e a individual. A natureza coletiva refere-se principalmente aos fatores determinantes pela cultura brasileira, marcada grandemente pela diversidade de referências étnicas condição esta que, talvez, contribua para um olhar mais plural e abrangente. Nas palavras do designer Cesar Robert Moraes de Sousa:

... entendo o designer brasileiro como um profissional que tem um olhar muito abrangente e multidisciplinar, por conta de toda a bagagem cultural que carrega e pelo ambiente sempre multifacetado e plural em que vive. (Entrevista concedida no dia 17/08/2015)

No polo oposto figuram características inerentes à personalidade deste profissional como otimismo e passionalidade. Curioso notar, ainda no âmbito das qualidades individuais, que as adversidades ao exercício da profissão e as contingências únicas do mercado nacional acabam por forjar características que são valoradas como positivas pelos entrevistados, dentre as quais pode-se destacar a flexibilidade, a persistência, empatia e até mesmo senso de humor. Estas características podem ser creditadas à outra qualidade frequentemente apontada, a criatividade, fruto talvez da necessidade de adaptação da prática profissional ao ambiente, muitas vezes pouco favorável, como aponta o designer Giorgio Giorgi:

... temos a nosso favor certa capacidade de improviso, fruto das vicissitudes da nossa condição. (Entrevista concedida no dia 05/10/2015)

Por outro lado, e infelizmente, os principais pontos fracos listados são, direta ou indiretamente ligados à qualidade da formação dos designers.

Ao se analisar os conselhos dados aos futuros designers percebe-se nitidamente um caráter motivacional ou educativo, estreitamente ligados aos desafios do exercício profissional que clamam por uma atitude perseverante e aprofundamento / especialização da educação formal do designer. Neste sentido, Cardoso (2012), assegura que:

A verdade é que ninguém se torna um profissional de qualquer área apenas por ter cursado a faculdade. O sistema universitário brasileiro reconhece isso ao exigir que o aluno faça um estágio profissionalizante, ou algo que o equivalha. Mesmo assim, vigora uma tendência nefasta em muitas áreas - dentre as quais o design - de considerar que o aluno ao terminar a faculdade já é um "profissional formado". Trata-se de uma 
distorção, responsável por gerar muita ansiedade e frustração desnecessárias. (CARDOSO, 2012, p. 232)

Por fim, no que diz respeito à opinião sobre a regulamentação da profissão, as respostas obtidas apontam para o quão polêmico é o tema. Aos que se manifestaram contrários ou indiferentes é comum o argumento de que o estado de coisas da profissão não seria diferente caso fosse regulamentada. Em contrapartida, a maioria dos entrevistados mostrou-se favorável à regulamentação, porem foram muito pouco os que o fizeram sem ressalvas. Fatores como um possível fisiologismo da representação da profissão, bem como possíveis enrijecimento das relações de trabalho e burocratização dos processos figuraram como condicionantes de uma resposta favorável.

\section{CONSIDERAÇÕES FINAIS}

Entendemos que a percepção dos pontos examinados pelo prisma dos agentes que os vivenciam clarificam o atual estado da arte e prospecta futuros cenários. As personalidades que colaboraram com nosso estudo, por meio de seus depoimentos, propiciaram um material coesivo com os assuntos indagados nos oferecendo condições de organizar um estudo condizente e norteador à perene construção de caminhos pedagógicos, investigativos e profissionais na área do design.

\section{REFERÊNCIAS}

BERNADES, Pedro P. D. Entrevista concedida ao Projeto de Pesquisa Design, Ponto de Vista e Perspectiva: sob a cultura do projeto, educação e atuação profissional. São Paulo, 2015.

BRAGA, Marcos C. Entrevista concedida ao Projeto de Pesquisa Design, Ponto de Vista e Perspectiva: sob a cultura do projeto, educação e atuação profissional. São Paulo, 2015.

BRANZI, Andrea. Introduzione al design italiano uma modernita incompleta. Milano: Baldini\&Castoldi, 1999.

CAMPOY, Rafael. Entrevista concedida ao Projeto de Pesquisa Design, Ponto de Vista e Perspectiva: sob a cultura do projeto, educação e atuação profissional. São Paulo, 2015.

CAPETO, Rodolfo R. S. Entrevista concedida ao Projeto de Pesquisa Design, Ponto de Vista e Perspectiva: sob a cultura do projeto, educação e atuação profissional. São Paulo, 2015.

CARDOSO, Rafael. Design para um mundo complexo. São Paulo: Cosac Naify, 2012. CURCIO, Gustavo. Entrevista concedida ao Projeto de Pesquisa Design, Ponto de Vista e Perspectiva: sob a cultura do projeto, educação e atuação profissional. São Paulo, 2015.

DE FUSCO, Renato. Design 2029, ipotesi per il prossimo futuro. Milano: Franco Angeli, 2012. 
GIORGI, G. Entrevista concedida ao Projeto de Pesquisa Design, Ponto de Vista e Perspectiva: sob a cultura do projeto, educação e atuação profissional. São Paulo, 2015.

HARADA, Fernanda J. B. Entrevista concedida ao Projeto de Pesquisa Design, Ponto de Vista e Perspectiva: sob a cultura do projeto, educação e atuação profissional. São Paulo, 2015.

LIN, Gloria. Entrevista concedida ao Projeto de Pesquisa Design, Ponto de Vista e Perspectiva: sob a cultura do projeto, educação e atuação profissional. São Paulo, 2015.

MAGER, Gabriela B. Entrevista concedida ao Projeto de Pesquisa Design, Ponto de Vista e Perspectiva: sob a cultura do projeto, educação e atuação profissional. São Paulo, 2015.

MARGOLIN, Victor. Design e risco de mudança. Matosinhos: Verso da História, 2014. MORACE, F. O que é o futuro? São Paulo: Estação das Letras e Cores, 2013.

NASCIMENTO, Myrna A. Entrevista concedida ao Projeto de Pesquisa Design, Ponto de Vista e Perspectiva: sob a cultura do projeto, educação e atuação profissional. São Paulo, 2015.

SILVA, J.C.R.P da; Et al. 0 futuro do design no Brasil. São Paulo: Cultura Acadêmica, 2012.

SOUSA, Cesar R. M. Entrevista concedida ao Projeto de Pesquisa Design, Ponto de Vista e Perspectiva: sob a cultura do projeto, educação e atuação profissional. São Paulo, 2015.

TRABUCCO, Francesco. Design. Torino: Bollati Boringhieri, 2015. 